\title{
Reflection on Integrating Traditional Handicrafts of Hubei Into the Professional Practice of Visual Communication Design
}

\author{
Lin Liu ${ }^{1}$ and Ziwei Xiao ${ }^{1, *}$ \\ ${ }^{1}$ College of Art and Design, Hubei University of Technology, Wuhan, Hubei 430068, China \\ * Corresponding author. Email: 1070352745@qq.com
}

\begin{abstract}
In order to protect and inherit the world's intangible cultural heritage and strengthen the attention of higher education in various countries to the traditional handicraft, this paper actively explores the integration of traditional handicraft practice into university design education. This paper uses the methods of literature analysis and field investigation. And it probes into the ways of integrating traditional handicrafts of Hubei into the teaching process, which is mainly reflected in the integration of practical teaching of major courses and field practice in university-enterprise projects. It puts forward that it's an indispensable factor for colleges and universities to create good hardware conditions in the integration of the practical teaching of traditional handicraft. In conclusion, the continuous development of Jingchu handicraft is inseparable from the implementation of Jingchu handicraft training in art design education in Colleges and universities.

Keywords: Handicraft in Hubei, Visual Communication Design, Professional Practice, Forms and Method
\end{abstract}

\section{INTRODUCTION}

In modern times, traditional handicraft skills were replaced by mass machine production during the industrial revolution, which has led to the disappearance of handiwork market and handicraft techniques. With the protection and inheritance of intangible cultural heritages in the world, higher education sectors of various countries attach greater and greater importance to traditional handicraft, thus promoting the exploration of the practical education of traditional handicraft in design majors of colleges and universities[4]. Through the integration of traditional handicraft of Hubei into the professional practice of Visual Communication Design, it can not only stimulate young students' interest in traditional handicraft, but also protect the cultural heritage.

\section{TEAM CONSTRUCTION OF TEACHERS OF TRADITIONAL HANDICRAFTS IN COLLEGES AND UNIVERSITIES}

\subsection{Research on the background of traditional handicraft of Hubei}

The unique geographical location and cultural atmosphere of Hubei have given birth to extremely splendid and colorful folk arts and formed influential handicrafts.
Relevant literature and museum exhibits have shown that during the Spring and Autumn Period and the Warring States Period, bronze, gold, jade, wood and lacquerware in Hubei had unique and realistic shapes, and some of the decorations were colorfully and elaborately made. The bronze plate and the lacquerware unearthed in Zenghouyi had reached an unprecedented level, and such achievements of handicraft had a great influence on the handicraft thoughts and industrial culture of Hubei in later ages[1]. After 1949, relevant departments of Hubei province carried out investigations on the folk handicrafts, and carried out renovation and counseling for craftsmen, which promoted the recovery and development of the traditional handicrafts in Hubei. According to the Investigation Report on the Folk Handicrafts in Hubei (printed and distributed in 1958), folk handicrafts in Hubei included carved paper cut, blue dyed cloth, colourful dyed cloth, brocade of Tu, embroidery, cross-stitch work, patch decoration, wood carving, nanmu inlaid decoration, wood plum blossom with gold lacquer, bamboo ware, bamboo weaving, pottery, lacquer, Hubei satin, velvet, stone carving, plaster carving, ink-stone carving, woodcut New Year painting, fan painting, shadow play, etc. Such handicrafts as embroidery, carpets, calligraphy, painting, and archaized porcelain began to be exported[6]. As an integral part of the intangible cultural heritage of the nation, traditional handicrafts in Hubei province have been gradually reducing, but their unique original cultural features and vigorous vitality have continued till today. As long as we study them, sort them out and dig them, they will surely become new living things. Integrating professional design into Hubei handicraft practice teaching can not only promote students' interest in learning 
handicrafts, but also be a means to protect Hubei traditional handicrafts.

\subsection{Teaching methods of traditional handicraft}

Traditional handicraft skills are taught by masters to their apprentices through a process of hands-on practice with guidance during the operation. Apprentices watch their masters do the work, work together with the masters and complete handicrafts under the direct guidance of the masters. At the same time, the precepts of masters and apprentices are passed down through subtle guidance. Although traditional handicraft skills have been gradually declining, they still have irreplaceable values for the education of art and design[7]. The teaching of traditional folk handicraft requires teachers to have solid skills of traditional handicrafts, and they should first have practical experience and the ability of hands-on operation. For a rather long time, colleges and universities have attached great importance to the educational background structure and professional title of teachers, while folk artists or handicraft masters do not meet the above requirements, making it difficult for them to become teachers. In addition, some young teachers are not enthusiastic enough about traditional folk handicrafts, which has inevitably caused difficulties in the integration of folk handicraft skills in major courses of design. In view of this, and in order to integrate the practical teaching of traditional handicrafts in Hubei, some universities have organized some academic lectures and training of traditional handicrafts. Lectures about such traditional handicrafts in Hubei as lacquerware, han embroidery, cross-stitch work, carved paper-cut and bamboo ware have been held, which has greatly benefited the teachers and the students. On July 2, 2017, our university co-organized the one-month course of "the Cultivation of Young Talents of Lacquerware Creation", a project sponsored by the national foundation of art, which attracted young university teachers from across the country and young teachers in our university. In this training event, a group of experts and scholars from the National Professional Committee of Lacquer Art, as well as professors from fine art institutes were invited to give lectures. They interpreted the language of lacquer, sorted out the evolution of lacquer art, summarized decoration techniques of lacquer painting and taught the trainees according to their aptitudes, thus providing guidance for the creation practice of the trainees. On July, 2018, our university held the exhibition for the completion of "Cultivation of Young Talents in the Repairing of Ancient Ceramics", a project sponsored by the National Foundation of Arts. Through the training, the students got the careful guidance of many top masters in the country. They helped each other and learned from each other, which helped them to deepen the understanding of ceramic repairing and improve their skills of repairing. In addition, in order to help young teachers have the capacity of guidance and teaching of traditional handicrafts, the university required some young teachers to regularly learn in research institutes of folk arts, workshops of handicrafts and companies of folk handiwork, and it required frequent organization of academic interaction and communication events, which has promoted the young teachers' practical level of traditional handicrafts.

\section{WAYS TO INTEGRATE TRADITIONAL HANDICRAFTS OF HUBEI INTO THE PRACTICAL TEACHING}

\subsection{Integration of professional courses into practical teaching}

The integration of the practical teaching of traditional handicrafts in professional design should be reflected in curriculum provision, that is, improving the selectivity and flexibility of courses, increasing the proportion of traditional handicrafts in major courses of design, widening the students' scope of knowledge about traditional handicrafts and improving the students' literacy of national culture. Major courses of visual communication design inherently have strong practical characteristics, and the main contents of the practical teaching of visual communication design cover basic sketching from nature (the second semester), collection of traditional culture (the fourth semester) and graduation investigation (the seventh semester). The collection of traditional culture (which involves two weeks outside the university and one week in the university) is a course focusing on the studying of traditional handicrafts. In this course, teachers lead their students to conduct field investigations in characteristic regions of folk arts, thus mastering the methods of field research in art and the collection and collation of materials, which can help cultivate the adaptability of the students and cultivate their spirit of unity, improve their knowledge of folk customs, write investigation reports and master the creation method of combining the restructuring of folk art elements with modern design. In order to understand and comprehend skills and methods of traditional handicrafts, it is mainly implemented in the course of traditional art collection and other major courses of design, such as copying the patterns on traditional lacquerware, patterns of han embroidery, cross-stitch work, xi lan ka pu, carved paper-cut and patch decoration, followed by recomposing of the patterns and drawing, selecting and extracting the design elements in them for application. This can improve the standard and attributes of commodities and endow the commodities with certain cultural connotations.

\subsection{Integration of school-enterprise project in practical teaching}

As educational places for cultivating high-level talents, colleges and universities of art have an inescapable responsibility in protecting and inheriting handicrafts. Since the actual teaching resources of colleges and 
universities can't enable them to independently shoulder the responsibility of inheritance, university-enterprise projects have become an effective way to support the integration of practical teaching of traditional handicrafts into the major of visual communication design. The integration of university-enterprise projects into the teaching process is a frequently used method to cultivate application-oriented talents. Especially, the combination of art design courses with projects is with the purpose of improving the knowledge and skills of the students through hands-on practice. The university where the authors work has established a batch of employment internship bases and studios co-constructed by the university and enterprises, which has created the conditions for practical teaching. In recent years, production projects have been carried out, such as the development and design of lacquerware tourist products of Hubei, package design of the Hubu Lane Liquor, image design of Jingwu duck neck, brand culture and creativity design of the Yellow Crane Tower, package design of Jinlongquan Beer and the design of Hubei-style porcelain plates. In this real practice, the students were required to deeply probe into the traditional handicrafts of Hubei and to dig or create application. Some new design proposals were recognized by enterprises and provided artistic inspirations for the project expansion of the enterprises. One example is the "Feng, Ya, Song" package design for the Hubu Lane, Feng, Ya and Song are three parts of the Book of Songs divided according to differences in music. In the conception of the package, we adopted such elements as bronze ware, lacquerware, glass ware, as well as golden and silver ware, which were recomposed and converted into the design of liquor vessels. The shapes, colors and texture language of these vessels clearly reflected the features of Chu culture. Another example is the package design of the Yellow Crane Tower Cigarettes, which incorporated the patterns of waves, auspicious clouds, paper-cut and embroidery, etc. The graphic design enhanced the cultural and regional characteristics of the products, and the tone of gold, yellowish-brown and red improved the standard and attribute of the product, and endowed it with certain cultural connotations. It's easy to see that they are the extension and expansion of traditional handicrafts of Hubei, as well as a measure to inherit and develop the excellent traditional culture of China.

\section{GOOD EXPERIMENTAL CONDITIONS ARE THE GUARANTEE FOR PRACTICAL TEACHING}

With the gradual improvement and development of higher art education in China, the experimental teaching system of art design in colleges and universities has presented an unprecedented trend of development[5]. In order to ensure the specific implementation of practical teaching of artistic design and strengthen the training of hands-on operation ability, it is particularly important to create good hardware conditions for teaching and training. In our university, there are already 9 provincial-and ministerial-level research bases and organizations (Hubei Intangible Cultural Heritage Research Center, Key Research Base of Humanities and Social Science in Hubei Province, Unit of the Chutian Scholar Program, Provincial Demonstration Center of Experimental Teaching, National Characteristic Major, Provincial Characteristic Subjects and Provincial Level-I Key Subjects, etc.) On that basis, the university also enhanced the positioning of university-enterprise practical teaching and established incubation and employment bases of folk art, thus ensuring the effective implementation of practical teaching of traditional handicrafts of Hubei. The school has built a provincial-level demonstration center of experimental teaching of art design, as well as sculpture studios, pottery studios, green ware rotating workshop, laboratory of silk screen dyeing, laboratory of photography, studios of folk decoration art, workshop of lacquerware, laboratory of environmental space, digital laboratory of packaging, CAD laboratories, laboratory of digital media, laboratories of carpentry and metalworking and art gallery for practical teaching. These practical platforms have created conditions for the integration of practical teaching of traditional handicrafts in Hubei.

The inheritance and development of traditional handicrafts should not be limited to classroom education, but should be combined with the establishment of on-campus training bases according to the categories of traditional handicrafts, including provincial museums, folk art galleries, fraternal universities, folk art research institutions and handicraft workshops, etc., which are important places for practicing traditional handicraft learning. Social resources should be open to students free of charge so as to broaden their access to knowledge of the traditional culture[3]. Therefore, it is necessary to establish a number of solid off-campus "industry-university-research" bases, including workshops of folk handicrafts, enterprises of folk art production and marketing organizations closely related to the local economic construction and development. This is an important link to ensure and satisfy the practical teaching of handicrafts. So far, the university has established 38 practical teaching bases outside the university, including bases related to the practical teaching of our major, such as the Fine Art Practical Base in Tuochuan Township, Wuyuan, Painting Base in Linlvshan, Henan, Painting Base in Hongcun Village, Anhui, Painting Bases in Dong Village and Miao Village in Guizhou, as well as such routes for traditional culture investigation as the Shaanxi-Dunhuang route, the Shanxi-Beijing route and the Henan-Xi'an route, etc. Besides, many other bases for professional practice have been established, including the Talent Cultivation Base for Practical Teaching Project Development in Wuhan Hongjinlong Printing Co.,Ltd., Practical Teaching Project Development Base in the Quilting Association of Zhejiang Province, Practical Teaching Project Development Base in Yingbo Jinlong Beer, Practical Teaching Base in Wuhan Jingyi Printing, Industrial Design Internship and Project Development Base in Foshan Daye, University-Enterprise Project Development \& Design Base in China Tobacco Hubei 
Industrial Co., Ltd, Teaching Base for the Synergetic Development Base of Aoke Holdings and Hubei University of Technology and the Synergetic Development Base of Bestore and Hubei University of Technology, etc. In addition, our major also arranges internships in production organizations of traditional handicrafts in the link of graduation practice. Through co-construction, relevant off-campus practical bases of traditional handicrafts have been promoted, which has created beneficial platforms for the combination of handicrafts in Hubei and the professional teaching of visual communication design.

\section{CONCLUSION}

With the development of the inheritance methods of skills, handicrafts in Hubei province have been constantly improved, gradually rising from individual skills to the memory carrier of national intangible culture. Inheriting such skills in the artistic practice teaching in colleges and universities is one of the effective ways to show the regional history and culture and civilization level. Only by cultivating the passion of young people for traditional handicrafts and letting them master handicraft skills in hands-on practice can protection and inheritance be realized. In the current era of the internet and information, science and technologies are applied to the production of products, and the work of traditional handicrafts is becoming less and less, and the hands are getting lazier and lazier. Keeping handicrafts is not only resistance against modern civilization, but it also involves environmental civilization, safe production and bionic cases. In our effort to protect and inherit handicrafts, we are not trying to preserve things, but to keep the spirit of handicrafts. Just like poems, they are the products of life that will not exist or perish because of the changes of times[2]. In the context of the national inheritance and protection of intangible cultural heritages, the continuation and development of handicrafts of Hubei cannot be realized without the cultivation of handicrafts of Hubei in the artistic design education in colleges and universities. Colleges and universities shall work as the initiators, teachers shall serve as the pacemakers, students should be the beneficiaries in the practice and folk artisans shall be hired as the bridges, so as to create good hardware conditions for teaching practice. People should accept it from the perspective of protecting national cultural heritages, so as to enable young students to feel and love traditional arts in the process of hands-on practice. Only by doing so can we integrate the beneficial thoughts and values of excellent traditional folk arts with the requirements of the times, thus promoting the inheritance and development of the cultural heritage of handicrafts in Hubei.

\section{REFERENCES}

[1] Chen Rihong. Jin Styles and Chu Rhymes-A Study on Folk Handicrafts of Hubei [M]. Culture and Art Publishing House, 2015: 37. (In Chinese)

[2] Gao Xing. Local Handicrafts in China [M] Shaanxi Normal University Press, 2004:270-272. (In Chinese)

[3] Sun Jingsong. A Brief Study on the Integration and Development of Traditional Culture in the Building of Practical Teaching Bases [J]. Chinese Vocational and Technical Education, 2012 (29):26-28. (In Chinese)

[4] Wang Wenzhang. An Outline of Intangible Cultural Heritages [M]. Culture and Art Publishing House, 2006:16. (In Chinese)

[5] Xia Jin. Experiments of Arts and the Art of Experiments [J] Design, 2017 (18):114-116. (In Chinese)

[6] Zhang Lang. Echos of Chu Arts--Zhang Lang's Literature of Arts and Crafts [M]. Hubei Fine Art Publishing House, 2009:71-86. (In Chinese)

[7] Zhao Li. A Brief Analysis of the Implication of Inheritance Methods of Traditional Handicrafts for Modern Education of Design [J] Shaanxi Education (Higher Education), 2015(7): 27-28. (In Chinese). 